Teknomekanik

Vol.4, No.2, Dec 2021, pp. 78 84

e-ISSN: 2621-8720 p-ISSN: 2621-9980

\title{
Quantitative Risk-Based Inspection on Gas Riser Pipelines at Offshore Facilities
}

\author{
Mhd. Ibkar Yusran Asfar ${ }^{1}$, Johny Wahyuadi Soedarsono ${ }^{\mathbf{1}}$, Arie Wijaya ${ }^{\mathbf{1}}$, \\ Taufik Aditiyawarman', Dony Soelistiyono ${ }^{3}$, Romal Ramadhan ${ }^{4}$ \\ ${ }^{1}$ Department of Metallurgy and Material Engineering, Faculty of Engineering, Universitas Indonesia \\ Depok 16424, Indonesia \\ 2 PT Pertamina Hulu Energi, Jakarta 12520, Indonesia \\ ${ }^{3}$ PT Pertamina Hulu Energi ONWJ, Jakarta 12520, Indonesia \\ ${ }^{4}$ Department of Mining and Petroleum Engineering, Faculty of Engineering, Chulalongkorn University, Bangkok 10330, \\ Thailand
}

\begin{tabular}{|c|c|}
\hline Article Info & ABSTRACT \\
\hline Article history: & Numerous pipeline failures have occurred due to the drastic increase in oil \\
\hline Received Aug 05 ${ }^{\text {th }}, 2021$ & and gas product distribution pipelines over the last three decades. Corrosion \\
\hline Revised Sep $25^{\text {th }}, 2021$ & maintain the integrity of the offshore transmission system, one of which is the \\
\hline Accepted Oct $31^{\text {th }}, 2021$ & $\begin{array}{l}\text { riser, for the product to be adequately distributed. The purpose of this study is } \\
\text { to ensure the riser's reliability by conducting a risk assessment of the }\end{array}$ \\
\hline Keywords: & $\begin{array}{l}\text { probability and consequences of equipment failure, mitigating the impact of } \\
\text { failure risk, and developing a more optimal inspection plan. The API } 5 \mathrm{~L} \text { Grade }\end{array}$ \\
\hline Quantitative & X60 gas riser pipe is the subject of this study. The quantitative Risk-Based \\
\hline Risk-Based Inspection & Inspection (RBI) technique was used in 2016 following the API 581 standard. \\
\hline Gas Pipeline & This quantitative approach is founded on a numerical value model constructed \\
\hline Offshore & using validated operational data and inspection results. The risk assessment \\
\hline Riser & $\begin{array}{l}\text { indicates that the gas riser pipelines will have a high-risk level }(5 D) \text { for the } \\
\text { splash zone segment and a medium-risk level }(2 D) \text { for the above-and below- } \\
\text { water segments. The recommended inspection plan for the gas riser pipeline } \\
\text { is one year after the risk-based inspection assessment. }\end{array}$ \\
\hline
\end{tabular}

\section{Corresponding Author:}

Mhd. Ibkar Yusran Asfar

Department of Metallurgy and Material Engineering, Faculty of Engineering, Universitas Indonesia

Depok 16424, Indonesia

Email: $\underline{\text { mhd.ibkar@ui.ac.id }}$

\section{INTRODUCTION}

Since the 1950s, pipelines have been one of the most practical, cost-effective, and safe methods of transporting large volumes of oil and gas over long distances between platforms. There has been a drastic increase in the installation of pipelines to distribute oil and gas over the last three decades [1]-[3]. Along with the increase in piping installations, they result in more failure problems found in the piping, such as damage or leaks in the piping system, resulting in accidents and explosions. Statistical data on pipeline failures in the United States in the last 20 years noted, there were a total of 288 incidents, 256 fatalities, and 1142 injuries with a total cost of loss of USD 10,713,774,726 [4]. Corrosion is the most significant percentage contributor to failure in offshore gas pipelines [5]. The system of offshore pipelines is known as a subsea flowline which describes the transmission of underwater pipelines to carry gas products from offshore platforms to onshore facilities [6], [7]. Companies need to make sure proper distribution of products by maintaining the integrity of equipment, some of which is located in offshore facilities. The approach that can be taken is to conduct a risk assessment of the likelihood and consequences of equipment failure. A risk assessment technique that can be used is the risk-based inception (RBI) method.

Numerous researchers have used the RBI method with a variety of approaches and modifications to assess risk in pipelines, such as Hameed et al. [8], who used the quantitative DNV RBI method to manage the integrity of oil and gas pipelines in the subsea. Song et al. [9] conducted a quantitative RBI analysis of high-energy pipe working at elevated temperatures and pressures in a power plant. The Weibull distribution with Mean Time to Failure (MTTF) and modification factors is used to estimate the probability of failure. Mediansyah et al. [10]

Journal homepage: http://teknomekanik.ppj.unp.ac.id

DOI: https://doi.org/10.24036/teknomekanik.v4i2.11172 
used the semi-quantitative RBI method to assess the risk associated with a 20-inch gas transmission pipeline in Central Java. Sommeng et al. [11] investigated the sensitivity of the risk assessment methodology used in Indonesia for gas distribution pipelines. The purpose of this study is to compare the risk and sensitivity results for six distribution pipelines using three risk assessment methodologies: muhlbauer, modified muhlbauer, and quantitative RBI. Sasikirono et al. [12] used the semi-quantitative RBI method to conduct a risk analysis on a 20-inch onshore gas transmission pipeline using corrosion rate parameters. Eskandarzade et al. [13] used a quantitative RBI approach to improve the quality of the analysis by removing the effects of bias associated with a qualitative approach. Seo et al. [14] evaluated corroded subsea oil pipelines using the RBI and fitnessfor-service (FFS) assessment. Lubis et al. [15] conducted a risk assessment of a gas pipeline using semiquantitative RBI and Fault Tree Analysis. Notably, there is still a scarcity of research on risk assessment in the pipe riser section. The riser is a section of pipe that connects the platform facility to the subsea pipeline directly. Priladi et al [7] had previously conducted research on risk assessment in gas riser pipelines. The risk assessment is conducted by the DNV-RP-F116 standard, utilizing the RBI technique with a qualitative approach. The research is focused on a 24-inch gas pipeline riser (DNV SAWL Grade 450 FUD) facility in an offshore. The results indicated that the gas riser pipelines risk value was medium-risk for the above-and below-water segments but high-risk for the splash zone segment. The purpose of this research is to apply a risk-based inspection method with a quantitative approach to the gas riser pipeline following the 2016 API 581 standard in order to assess the level of risk, mitigate the impact of any potential failure, and plan a more optimal inspection.

\section{METHODS}

The research is focused on the Riser export of PT XYZ, which is connected to the subsea gas pipeline at an offshore facility. The pipe specifications are API 5L Grade X60 standard with a nominal diameter of 26inch and a wall thickness of $14.275 \mathrm{~mm}$. Research data is based on in-line inspection reports (ILI) using highresolution Magnetic Flux Leakage (MFL). The risk assessment is carried out based on a quantitative approach to risk-based inspection according to the 2016 API 581 standard by analyzing and evaluating the corrosion rate from the ILI inspection data.

\subsection{Risk-based Inspection}

Risk-based inspection (RBI) is a risk assessment and management technique centered on the containment loss of pressurized equipment in processing facilities as a result of damage mechanisms. These dangers are largely mitigated by routine equipment examination. Risk-based inspection planning is carried out using a quantitative approach method. This approach is based on a numerical value model that is calculated from validated data. The probability and consequences of failure are combined to produce a risk estimate for the equipment. The result of the approach is a risk rating with a matrix of the probability of failure and the consequences of failure. This approach is more precise than the qualitative approach because it uses valid data obtained from the results of the ILI inspection and other supporting documents. Risk/ total risk is defined quantitatively by the RBI as the product of the probability of failure (POF) and the consequences of failure (COF), as specified in Equation 1. Then, in accordance with API 581 [16], the risk level is assessed using a 5X5 risk matrix [16]. High-risk equipment should prioritise inspection more than low-risk equipment; that is, high-risk equipment requires more frequent inspections and/or more strict inspection approaches to mitigate risk [17], [18].

$$
\text { Risk }=P O F \times C O F
$$

\subsection{Probability of Failure}

Probability of failure (POF) of an equipment or component as a result of a single or many damage mechanisms happening under specified operating circumstances. Based on the quantitative RBI method, the probabilities are identified using the generic failure frequency, damage factor, and system management factor. The API 581 standard guides the probability of failure in part 2, namely the probability of failure methodology, which can be determined using the following Equation 2 [16].

$$
P O F=g f f_{\text {total }} \times D_{f}(t) \times F_{M S}
$$

The general failure factor (gff) indicates the frequency with which each piece of equipment fails with units of failure per year. The general failure factor is intended to represent the frequency of failure before specific damage occurs due to exposure to the operating environment. It is provided for various hole sizes for various types of processing equipment, including compressors, heat exchangers, piping, pressure vessels, drums, and tanks.

\footnotetext{
Journal homepage: http://teknomekanik.ppj.unp.ac.id

DOI: https://doi.org/10.24036/teknomekanik.v4i2.11172
} 
The damage factor $\left(D_{f}(t)\right)$ is determined by the type of damage, which may include general/local thinning, external damage, stress corrosion cracking (SCC), high-temperature hydrogen attack (HTHA), mechanical fatigue, and brittle fracture. Damage factor can be calculated using Equation 3 [16]. Not all of these possibilities must be considered when calculating the damage factor; instead, the most recent inspection data and historical failures must be considered.

$$
D_{f}(t)=D_{f}^{\text {thin }}+D_{f}^{\text {extd }}+D_{f}^{s c c}+D_{f}^{\text {htha }}+D_{f}^{\text {brit }}+D_{f}^{\text {mfat }}
$$

The management system factor is an adjustment factor that considers the effect of the facility management system on the equipment's mechanical integrity. This factor is determined by the results of the facility or operating unit management system evaluation that affects the installation risk. Management system evaluation is presented in the API 581 standard in Annex 2. A. The evaluation contains questions whose scores are then entered into the following Equation 4 [16].

$$
\text { pscore }=\frac{\text { score }}{1000} \times 100[\text { unit is } \%]
$$

Then the score value is entered into Equation 5 below to get the management system factor value [16].

$$
F_{M S}=10^{((-0.02 \times \text { pscore })+1)}
$$

\subsection{Consequence of Failure}

A consequence of failure (COF) is an event that occurs as a result of equipment failure. There are two approaches to determining the COF value, namely based on area-based risk and financial-based risk [16]. This research, however, is limited to area-based risk, as the supporting data are sufficient to determine the value of failure's consequences. In general, the area-based risk can be predicted through a series of stages, including selecting a representative fluid, the leak hole's size, and the fluid phase following a leak. The next step is to determine the rate of leakage, the type of leak, the response to a leak, the impact of leakage, the generic damage fraction, and the extent of failure consequences. The API 581 standard includes a formula for calculating the consequences of failure in detail. The final value of the failure consequences is determined by comparing the final component damage $\left(\mathrm{CA}_{\mathrm{cmd}}\right)$ and final personnel injury $\left(\mathrm{CA}_{\mathrm{inj}}\right)$, with the highest value determining the failure consequence category as defined in Equation 6 [16].

$$
C A=\max \left[C A_{c m d}, C A_{\text {inj }}\right]
$$

\subsection{Segmentation}

Segmentation is the process of dividing a pipeline into sections to collect as much information as possible from the analyzed assets. This is because each pipe has unique characteristics that are influenced by mechanical conditions and the pipe environment. As a result, the risk level along the pipeline varies in terms of failure probability and consequence [14], [19], [20]. Segmenting the riser into three sections is possible. These sections are above water, splash zone, and below water [7]. The above water segment is the riser pipe section after the valve block flange connection from the pigging facility to the mean sea level. Below water segment is located between the mean sea level and the riser bend under seawater. The Splash zone segment is between the seawater boundary (the upper part of the splash zone area) and the lower seawater boundary [21].

\section{RESULTS AND DISCUSSION}

\subsection{In-Line Inspection (Report)}

The data used for risk assessment is collected through in-line inspection activities using a high-resolution MFL. The data obtained contains metal loss, defect geometry, depth and length of defects, types of defects, and location of defects, as shown in Table 1. Based on data from the ILI inspection, only the splash zone segment has corrosion and a reduction in pipe thickness, while in the above-and below-water, there is no issue of reducing pipe thickness. The metal loss that occurs in the splash zone segment is $64 \%$ of the initial thickness. Based on the maximum allowable thickness standard, the splash zone segment is still included in the safe category to operate because it is less than $80 \%$ of the nominal pipe wall thickness [22]. Meanwhile, PT XYZ increased the riser's safety margin to $70 \%$ of the nominal pipe wall thickness [21].

Journal homepage: http://teknomekanik.ppj.unp.ac.id

DOI: https://doi.org/10.24036/teknomekanik.v4i2.11172 
Table 1: Riser Inspection Data

\begin{tabular}{llllll}
\hline Segment & $\begin{array}{l}\text { Metal Loss } \\
(\%)\end{array}$ & $\begin{array}{l}\text { Width } \\
(\mathbf{m m})\end{array}$ & $\begin{array}{l}\text { Length } \\
(\mathbf{m m})\end{array}$ & $\begin{array}{l}\text { Anomaly } \\
\text { Dimension } \\
\text { Class }\end{array}$ & Location \\
\hline Above Water & 0 & 0 & 0 & - & - \\
Splash Zone & 64 & 430 & 49 & General & External \\
Below Water & 0 & 0 & 0 & - & - \\
\hline
\end{tabular}

\subsection{Probability of Failure}

The probability is determined by Equation 2, which corresponds to part 2 of the 2016 API 581 standard [16]. The total value of generic failure frequencies $\left(\mathrm{gff}_{\text {total }}\right.$ ) used is the component type PIPE-16 because the largest nominal pipe size (NPS) available in this standard is 0.00000306 failures/year. The management system factor is assumed to have a total score of 500. Meanwhile, the damage mechanism based on ILI inspection data shows that only thinning and external mechanisms occur. The pipe corrosion rate for each segment is calculated by comparing the initial and actual thickness with a specific period [23]. The splash zone segment demonstrates that the remaining pipe thickness is $5.137 \mathrm{~mm}$ at a corrosion rate of $0.46 \mathrm{~mm} / \mathrm{year}$. The minimum allowable pipe thickness can be determined using the ASME B31.4 standard [24]. The loss fraction of pipe wall components $\left(\mathrm{A}_{\mathrm{rt}}\right)$ is determined based on the actual thickness, corrosion rate, and RBI time difference with the last inspection. In Table 2 can be seen the details of the data and categories of the probability of failure. The category for each pipe segment is different; the splash zone segment is in category 5 because it experiences a reduction in thickness and external corrosion. In contrast, the above-and below-water sections are in category 2 because there are no issues of thinning of pipe walls and corrosion in those areas.

Table 2: Probability of Failure on Riser

\begin{tabular}{lllllll}
\hline Segment & $\begin{array}{l}\text { Thickness } \\
\text { Actual }(\mathbf{m m})\end{array}$ & $\begin{array}{l}\text { Corrosion Rate } \\
(\mathbf{m m} / \mathbf{y e a r})\end{array}$ & $\mathbf{A}_{\mathbf{r t}}$ & $\begin{array}{l}\text { Damage Factor } \\
\text { Total }\end{array}$ & $\begin{array}{l}\text { POF (failure/ } \\
\text { year) }\end{array}$ & $\begin{array}{l}\text { Category } \\
\text { POF }\end{array}$ \\
\hline Above Water & 14.275 & 0 & 0 & 4.350 & $1.33 \mathrm{E}-04$ & 2 \\
Splash Zone & 5.139 & 0.46 & 0.71 & 12820.426 & 0.392 & 5 \\
Below Water & 14.275 & 0 & 0 & 4.350 & $1.33 \mathrm{E}-04$ & 2 \\
\hline
\end{tabular}

\subsection{Consequence of Failure}

The consequences of failure are determined by the area affected if the pipeline fails and is calculated using the calculation of consequences in part 3 of the API 581 standard. In calculating the consequences of failure, there are several assumptions given, such as [16]:

1) The consequences are calculated using area-based risk (CA).

2) Analysis is calculated based on level 1 consequences.

3) The mass release rate ranges from $45.4 \mathrm{~kg}$ to $45.3592 \mathrm{~kg}$.

4) Leakage hole ranging in size from $6.35 \mathrm{~mm}$ to $406 \mathrm{~mm}$

Determination of the consequences of failure is done by comparing the maximum value of total component damage with personnel injury according to Equation 6. Table 3 shows the final scores for the consequences of failure and their categories. Based on the results of the RBI quantitative analysis, the consequences of failure of each riser pipe segment are predicted in category $\mathrm{D}$. The factor that causes the COF category of each riser segment to be the same is that they are on the same operating system. Therefore, the input data used during the analysis is also the same.

Table 3: Consequence of Failure on Riser

\begin{tabular}{llllllll}
\hline $\begin{array}{l}\text { Release } \\
\text { Hole Size }\end{array}$ & $\begin{array}{l}\text { Release } \\
\text { Hole } \\
\text { Diameter } \\
(\mathbf{m m})\end{array}$ & Release Type & $\begin{array}{l}\text { Component } \\
\text { Damage CA } \\
\left(\mathbf{m}^{\mathbf{2}}\right)\end{array}$ & $\begin{array}{l}\text { Personnel } \\
\text { Injury CA } \\
\left(\mathbf{m}^{\mathbf{2}}\right)\end{array}$ & $\begin{array}{l}\text { Final } \\
\text { Component } \\
\text { Damage CA } \\
\left(\mathbf{m}^{\mathbf{2}}\right)\end{array}$ & $\begin{array}{l}\text { Final } \\
\text { Personnel } \\
\text { Injury CA } \\
\left(\mathbf{m}^{\mathbf{2}}\right)\end{array}$ & $\begin{array}{l}\text { Category } \\
\mathbf{C O F}\end{array}$ \\
\hline Small & 6.4 & Continuous & 18.457 & 45.367 & & & \\
Medium & 25 & Instantaneous & 1139.303 & 2194.442 & 1214.031 & 2340.922 & $\mathrm{D}$ \\
Large & 102 & Instantaneous & 2545.120 & 4902.180 & & & \\
Rupture & 406 & Instantaneous & 15208.888 & 29293.978 & & \\
\hline
\end{tabular}

Journal homepage: http://teknomekanik.ppj.unp.ac.id

DOI: https://doi.org/10.24036/teknomekanik.v4i2.11172 


\subsection{Risk Ranking}

The results of a quantitative approach to calculating POF and COF indicate that the risk ranking for each segment is distinct. The pipe segment in the splash zone has a risk ranking of 5D (high-risk), whereas the above-and below-water segments have a risk ranking of 2D (medium-risk), as seen in Figure 1. Further examination reveals that the reason for the gas riser pipeline segment's varying rankings is the mechanism of damage. There is a loss of pipe wall thickness and external corrosion of $64 \%$ of the initial pipe thickness in the splash zone segment. Meanwhile, neither the above-and below-water segments of the pipe exhibit any signs of thinning or corrosion.

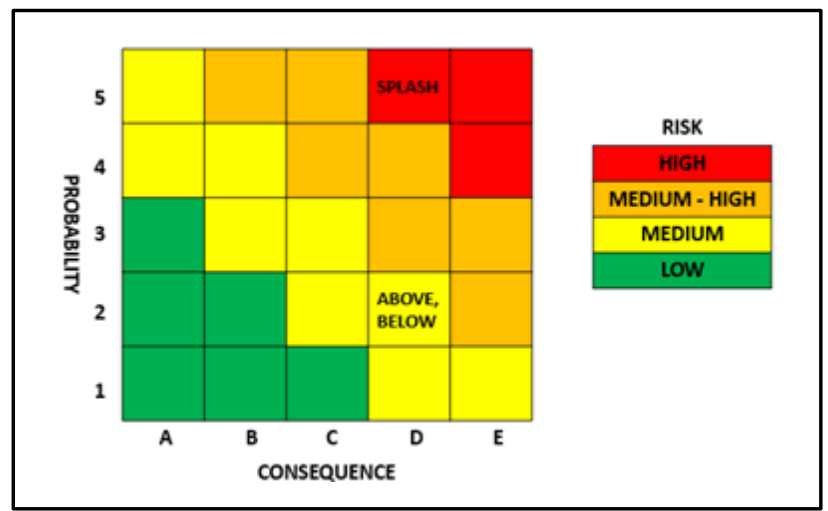

Figure 1: Riser Risk Matrix

\subsection{Risk Mitigation}

Environmental conditions cause a high-risk of failure in the splash zone pipe segment. The splash zone is the part of the pipeline that experiences wetting due to high and low tides. The height of the rise and fall of seawater depends on the geography of each pipeline installation area. Pipes that experience continuous wetting and drying due to tides can accelerate external corrosion, especially on metal materials. Additional monitoring of the splash zone segment is required immediately to prevent pipeline equipment failure in the future. Risk mitigation measures include repairing or enhancing the protective layer using a cathodic protection system [25] and wrapping method [21]. The 64\% reduction in wall thickness in the splash zone segment indicates that the coating layer has failed. Therefore, a more appropriate recommendation for improvement is reinforcing the pipe using the wrapping method.

\subsection{Inspection Planning}

The 2016 API 581 standard does not explain how to plan an inspection schedule in detail or with specific equations; instead, it is illustrated graphically [16]. The term "inspection planning" refers to the process of determining the defined risk targets. Certain assumptions are made in order to develop the inspection plan:

1) Set a risk target of $918 \mathrm{~m}^{2} /$ year.

2) The company has specified a ten-year inspection plan from the date of the last inspection.

3) Determination of inspection plans based on high-risk equipment.

As shown in Table 4, the total risk is predicted to reach the target risk in October 2022. As a result, the recommended inspection interval following the risk-based inspection assessment is one year. Meanwhile, the company has set an inspection date of October 2023, and it is anticipated that the total risk will exceed the predetermined risk target.

Table 4: Recommendation Inspection Planning for Gas Riser Pipeline

\begin{tabular}{llllll}
\hline \multicolumn{2}{c}{ Date } & $\begin{array}{l}\text { Damage } \\
\text { Factor } \\
\text { Total }\end{array}$ & $\begin{array}{l}\text { POF } \\
\text { (failure/ } \\
\text { year })\end{array}$ & COF $\left(\mathbf{m}^{\mathbf{2}}\right)$ & $\begin{array}{l}\text { Risk } \\
\left(\mathbf{m}^{2} / \mathbf{y e a r}\right)\end{array}$ \\
\hline October, 2013 & Last Inspection & 6185.842 & 0.189 & 2340.922 & 442.434 \\
October, 2021 & RBI Date & 12820.426 & 0.392 & 2340.922 & 917.641 \\
October, 2023 & Plan Date & 12820.499 & 0.392 & 2340.922 & 918.361 \\
October, 2022 & Risk Target & 12820.462 & 0.392 & 2340.922 & 918 \\
\hline
\end{tabular}




\subsection{Discussion}

A quantitative approach confirms that the gas riser pipelines from the splash zone segment are at a highrisk level, based on the risk assessment conducted in this study using the RBI method. Meanwhile, both aboveand below-water are considered to be at a medium-risk level. The study found that damage mechanisms such as thinning and external corrosion on the pipe walls affect risk. Comparing the results of this study to those of Priladi et al. [7] demonstrates that the level of risk is comparable, but distinct factors influence that risk assessment. In-line inspection, cathodic protection, free-span, and marine growth all affect the POF assessment. ILI results indicate that metal loss is $0 \%$ for each pipe segment, meaning no thinning occurs. The final POF assessment, weighted by scoring, identifies categories 2 (above-and below-water) and 3 (splash zone). The COF assessment is influenced by factors of environmental, safety, a threat to an asset, and public reputation. The component determines the final COF score with the lowest score among the four, which indicates it is in category 5. Additionally, differences were discovered in the risk matrix's configuration. The DNV standard provides an equation for determining the inspection plan, which recommends a 1.5 -year inspection plan for inline inspection. As demonstrated in this study, POF is influenced by several factors, including generic failure frequency, damage factor, and system management factor. COF determination is influenced by factors of component damage and personnel injuries. The quantitative approach used to determine the POF and COF categories is based on the development of a numerical model using validated data. It entails a higher level of precision and data collection than the qualitative approach does. The API 581 standard determines inspection planning based on the total risk that touches the risk target value.

\section{CONCLUSION}

According to the risk assessment conducted by the RBI quantitative method for the 26-inch gas riser pipeline, the risk level for the above-and below-water segments is predicted to be medium-risk (2D). While the splash zone segment is predicted to be high-risk (5D). Due to the influence of operating data, the consequences of failure are similar for each segment. The influence of the environment, which causes external corrosion, is a factor that affects the probability of failure in the splash zone segment. Reduce the risk of failure by increasing the effectiveness of inspections and reinforcing the pipe using the wrapping method. The recommended inspection plan for the gas riser pipeline using the in-line inspection method is one year from the date of the risk-based inspection assessment, i.e., October 2022.

\section{REFERENCES}

[1] G. Pluvinage, "General Approaches of Pipeline Defect Assessment," Safety, Reliab. Risks Assoc. with Water, Oil Gas Pipelines, pp. 1-22, Dec. 2007, doi: 10.1007/978-1-4020-6526-2_1.

[2] W. Yu et al., "A novel methodology to update the reliability of the corroding natural gas pipeline by introducing the effects of failure data and corrective maintenance," Int. J. Press. Vessel. Pip., vol. 169, pp. 48-56, Jan. 2019, doi: 10.1016/J.IJPVP.2018.11.001.

[3] M. Xie and Z. Tian, "A review on pipeline integrity management utilizing in-line inspection data," Eng. Fail. Anal., vol. 92, pp. 222-239, Oct. 2018, doi: 10.1016/J.ENGFAILANAL.2018.05.010.

[4] US DOT Pipeline and Hazardous Materials Safety Administration, "PHMSA Pipeline Incidents: MultiYear Averages (2001-2020),” Oct. 2021. Accessed: Oct. 12, 2021. [Online]. Available: https://portal.phmsa.dot.gov/analytics/saw.dll?Portalpages\&PortalPath=\%2Fshared\%2FPDM Public Website\%2F_portal\%2FSC Incident Trend\&Page=Significant.

[5] M. J. Baker, "Pipeline Corrosion Final Report,” Nov. 2008. Accessed: Oct. 12, 2021. [Online]. Available: https://www.phmsa.dot.gov/sites/phmsa.dot.gov/files/docs/technical-resources/pipeline/gastransmission-integrity-management/65341/finalreportpipelinecorrosion.pdf.

[6] Y. Bai and Q. Bai, Subsea Pipelines and Risers (Ocean Engineering). 2005.

[7] H. Priladi, J. W. Soedarsono, D. Nurprawito, and F. Perdana, "Risk Assessment on Riser at Offshore Facilities," in International Engineering Students Conference (IESC) 2021, 2021, pp. 64 (1-5).

[8] H. Hameed, Y. Bai, and L. Ali, "A risk-based inspection planning methodology for integrity management of subsea oil and gas pipelines," Ships Offshore Struct., vol. 0, no. 0, pp. 1-13, 2020, doi: 10.1080/17445302.2020.1747751.

[9] J. S. Song, V. Lok, K. B. Yoon, Y. W. Ma, and B. O. Kong, "Quantitative risk-based inspection approach for high-energy piping using a probability distribution function and modification factor," Int. J. Press. Vessel. Pip., vol. 189, p. 104281, 2021, doi: 10.1016/j.ijpvp.2020.104281.

[10] Mediansyah, G. D. Haryadi, R. Ismail, and S. J. Kim, "Risk Analysis of Central Java Gas Transmission Pipeline by Risk-Based Inspection Method," IOP Conf. Ser. Mater. Sci. Eng., vol. 202, no. 1, 2017, doi: 10.1088/1757-899X/202/1/012094.

[11] A. N. Sommeng et al., "Sensitivity analysis of gas distribution pipeline risk assessment methodology in

Journal homepage: http://teknomekanik.ppj.unp.ac.id

DOI: https://doi.org/10.24036/teknomekanik.v4i2.11172 
Indonesia," AIP Conf. Proc., vol. 2230, no. May, 2020, doi: 10.1063/5.0002612.

[12] B. Sasikirono, S. J. Kim, G. D. Haryadi, and A. Huda, "Risk Analysis using Corrosion Rate Parameter on Gas Transmission Pipeline,” IOP Conf. Ser. Mater. Sci. Eng., vol. 202, no. 1, 2017, doi: 10.1088/1757899X/202/1/012099.

[13] M. Eskandarzade, R. M. Chandima Ratnayake, and M. Najafi Ershadi, "Mechanization of qualitative risk based inspection analysis," IEEE Int. Conf. Ind. Eng. Eng. Manag., vol. 2020-Decem, pp. 401-406, 2020, doi: 10.1109/IEEM45057.2020.9309754.

[14] J. K. Seo, Y. Cui, M. H. Mohd, Y. C. Ha, B. J. Kim, and J. K. Paik, “A risk-based inspection planning method for corroded subsea pipelines," Ocean Eng., vol. 109, pp. 539-552, Nov. 2015, doi: 10.1016/J.OCEANENG.2015.07.066.

[15] M. O. Z. A. Lubis, A. Widodo, and G. D. Haryadi, "Risk Assessment of Gas Pipeline using Risk based Inpection and Fault Tree Analysis," no. Eic 2018, pp. 43-47, 2020, doi: 10.5220/0009006100430047.

[16] American Petroleum Institutes (API), Risk-Based Inspection Methodology API RP 581, Third Edit. Washington, DC 20001: API Publishing Services, 2016.

[17] A. Rachman and R. M. C. Ratnayake, "Machine learning approach for risk-based inspection screening assessment," Reliab. Eng. Syst. Saf., vol. 185, pp. 518-532, May 2019, doi: 10.1016/J.RESS.2019.02.008.

[18] J. T. Reynolds, "Risk Based Inspection - Where Are We Today?," CORROSION 2000. Mar. $26,2000$.

[19] R. Amaya-Gómez, M. Sánchez-Silva, and F. Muñoz, "Integrity assessment of corroded pipelines using dynamic segmentation and clustering," Process Saf. Environ. Prot., vol. 128, pp. 284-294, 2019, doi: https://doi.org/10.1016/j.psep.2019.05.049.

[20] L. A. Malik, J. W. Soedarsono, M. S. Yudim, and R. Riastuti, "Risk based inspection of corroded gas pipelines," Int. J. Mech. Prod. Eng. (IJMPE)-IJMPE, vol. 8, no. 10, pp. 1-4, 2020, [Online]. Available: http://ijmpe.iraj.in/paper_detail.php?paper_id=17604\&name=Risk_based_Inspection_of_Corroded_Gas _Pipelines.

[21] P. P. ONWJ, “Tata Kerja Organisasi Pedoman Perbaikan Riser,” PHEONWJ-W-TKO-0020, 2020.

[22] The American Society of Mechanical Engineers, ASME B31G - Manual for Determining the Remaining Strength of Corroded Pipelines. New York, NY 10016-5990: The American Society of Mechanical Engineers, 2009.

[23] American Petroleum Institutes (API), Piping Inspection Code: In-service Inspection, Rating , Repair , and Alteration of Piping Systems API 570, Fourth Edi. Washington, DC 20005: API Publishing Services, 2016.

[24] ASME B31.4, Pipeline Transportation Systems for Liquids and Slurries. New York, NY 10016-5990: The American Society of Mechanical Engineers, 2019.

[25] R. Singh, Corrosion Control for Offshore Structures, 1st Editio. United Kingdom, UK: Gulf Professional Publishing, 2014.

\section{NOMENCLATURE}

$C A \quad$ meaning of consequence impact area $\left(\mathrm{m}^{2}\right)$

$C A_{\text {cmd }}$ meaning of final component damage consequence area $\left(\mathrm{m}^{2}\right)$

$C A_{\text {inj }} \quad$ meaning of final personnel injury consequence area $\left(\mathrm{m}^{2}\right)$

$D_{f}(t) \quad$ meaning of the damage factor as a function of time, equal to $D_{f \text {-total }}$ evaluated at a specific time

$D_{f}^{\text {thin }} \quad$ meaning of the damage factor for thinning

$D_{f}^{\text {extd }}$ meaning of the damage factor for external damage

$D_{f}^{S C C} \quad$ meaning of the damage factor for stress corrosion cracking (SCC)

$D_{f}^{\text {htha }} \quad$ meaning of the damage factor for high temperature hydrogen attack (HTHA)

$D_{f}^{\text {brit }} \quad$ meaning of the damage factor for brittle fracture

$D_{f}^{m f a t} \quad$ meaning of the damage factor for mechanical fatigue

$F_{M S} \quad$ meaning of the management system factor

$g f f_{\text {total }}$ meaning of the sum of the individual release hole size generic frequencies (failures/year)

pscore meaning of the management systems evaluation score expressed as a percentage

score meaning of the score obtained from the management systems evaluation 